\title{
Larvicidal Activity of the Essential Oil from Lippia sidoides Cham. against Aedes aegypti Linn.
}

\author{
Ana Fontenele Urano Carvalho/ ${ }^{+}$, Vânia Maria Maciel Melo, Afrânio Aragão Craveiro*, \\ Maria Iracema Lacerda Machado*, Márcia Braga Bantim, Emanuelle Fontenele Rabelo
}

\author{
Departamento de Biologia *Parque de Desenvolvimento Tecnológico, Universidade Federal do Ceará, Campus do Pici, \\ 60455-900 Fortaleza, CE, Brasil
}

The aim of this work was to study the larvicidal activity of Lippia sidoides essential oil against Aedes aegypti larvae. The essential oil and its hydrolate (saturated solution of essential oil in water) were obtained by vapor extraction and their chemical composition determined by GL-chromatography coupled to mass spectroscopy. Bioassays were run with the essential oil, pure and diluted hydrolate and with their main constituents thymol and carvacrol. The results obtained showed that $\mathrm{L}$. sidoides essential oil and its hydrolate have larvicidal action against the mosquito $\mathrm{A}$. aegypti, causing an almost instantaneous mortality. Thymol, an alkylated phenol derivative and one of the major components of $\mathrm{L}$. sidoides essential oil, was identified as the active principle responsible for the larvicidal action, causing $100 \%$ larval mortality at the lowest tested concentration of $0.017 \%(\mathrm{w} / \mathrm{v})$. These results suggest that the essential oil of $\mathrm{L}$. sidoides is promising as larvicide against $\mathrm{A}$. aegypti and could be useful in the search of newer, more selective, and biodegradable larvicidal natural compounds to be used in official combat programs and at home.

Key words: Lippia sidoides - larvicidal activity - thymol

Mosquitoes are responsible for more diseases than any other group of arthropods (Cepleanu 1993). The mosquito Aedes aegypti acts as a vector for an arbovirus responsible for yellow fever in Central and South America and in West Africa. It is also the vector of dengue hemorrhagic fever, which is endemic to South East Asia, the Pacific islands area, Africa and the Americas (Maillard et al. 1993). Indeed, the present recrudescence of these diseases is due to the higher number of breeding places in today's throwaway society and to the increasing resistance of mosquitoes to current commercial insecticides. Although yellow fever has been reasonably brought under control with its vaccine, no vaccine is available for dengue. The only way of decreasing the incidence of this disease is thus the combat to A. aegypti. Experience has shown that aerial toxicants for the control of this mosquito are not effective, since it is highly domesticated and many adults rest indoors in hidden places such as closets. The only successful way of reducing mosquito densities to a level where dengue or yellow fever epidemics do not occur is by attacking the larval breeding places (Gluber 1989). The ideal control method is thus the systematic treatment of their breeding places through larvicides. The main agents used are insecticidal and larvicidal organophosphorates. An alternative for conventional chemical control is the utilization of natural products from

\footnotetext{
${ }^{+}$Corresponding author. Fax: $+55-85-288.9806$.

E-mail: aurano@ufc.br

Received 17 October 2002

Accepted 25 March 2003
}

plants (Consoli \& Oliveira 1994). In fact, numerous plants have been shown to produce compounds with pesticidal activity, as a chemical defense mechanism against either predation or infection. The species Lippia sidoides Cham. (Verbenaceae), known in Brazil by the names "alecrimpimenta" or "estrepa-cavalo" is a typical shrub from Northeastern Brazil vegetation; it is highly branched with aromatic flowers and is commonly found in the dry Northeast of Brazil, from Mossoró (Rio Grande do Norte) to Tabuleiro do Norte (Ceará) (Matos 1994). This species produces an essential oil with potent antimicrobial action against fungi and bacteria, which is utilized for several skin complaints (Matos 1994).

The aim of this work was to investigate the larvicidal activity of the essential oil from $L$. sidoides against $A$. aegypti in the search for an alternative natural product, which can be used in the control of recurrent dengue epidemics.

Shoots from $L$. sidoides were obtained from the medicinal Plant Garden of the Federal University of Ceará. A voucher numbered 21926 was deposited in the Herbarium Prisco Bezerra at the same Institution.

The essential oil from $L$. sidoides was obtained from shoot samples $(1 \mathrm{~kg})$ by steam distillation during $90 \mathrm{~min}$. This procedure produces the essential oil and the co-distilled water, called hydrolate. The chemical composition of the hydrolate was determined by GL-chromatography coupled to mass spectroscopy performed on a HewlettPackard 5971 GC/MS instrument employing the following conditions: polydimethylsiloxane DB-1 fused silica capillary colums ( $30 \mathrm{~m} \times 0.25 \mathrm{~mm}$ ), with film thickness $0.10 \mu \mathrm{m}$; the carrier gas was helium $(1 \mathrm{ml} / \mathrm{min})$, the injector temperature was $250^{\circ} \mathrm{C}$ whilst the detector temperature was $200^{\circ} \mathrm{C}$. 
The column temperature ranged from 35 to $180^{\circ} \mathrm{C} / \mathrm{min}$, at $4^{\circ} \mathrm{C} \mathrm{V} / \mathrm{min}$, then from 180 to $280^{\circ} \mathrm{C}$, at $20^{\circ} \mathrm{C} \mathrm{V} / \mathrm{min}$; mass spectra were obtained by electronic impact $70 \mathrm{eV}$.

Eggs of A. aegypti were obtained from Cetrav (Célula de Controle de Endemias Transmissíveis por Vetores Secretaria de Saúde, Ceará) in dehydrated form, adsorbed on paper strips. Approximately $10 \mathrm{~cm}^{2}$ of paper strips holding the eggs were placed in a rectangular polyethylene recipient $(35 \times 25 \times 7 \mathrm{~cm})$ containing distilled water and about $20 \mathrm{mg}$ of rabbit stock diet (Purina, São Paulo, Brazil). The recipient was kept at room temperature for hatching and monitoring of larval development for one-week period. The larvae then between third and fourth stages were collected according to larval size and the degree of chitinization of the respiratory siphon (Bantim 2000).

The larvae toxicity assay was made according to Thangam and Kathiresan (1991), with some modifications. Third stage larvae were collected with a Pasteur pipette, placed on filter paper for removal of excess water and transferred (20 per test) with a tiny brush into beakers containing $25 \mathrm{ml}$ of test solution. Tests were run with the essential oil, with pure and diluted hydrolate $(1: 2 ; 1: 5$; $1: 10$ and $1: 20, v / v)$, and with thymol and carvacrol (Sigma Co., USA), main constituents of the essential oil. These were tested at concentrations of their respective solubility coefficients in water $(0.085 \%$ thymol and $0.04 \%$ carvacrol), in Tween- 80 at $0.04 \%$. Thymol was also tested at $0.04 ; 0.017$ and $0.008 \%$. For comparative purposes tests were run concomitantly with the larvicidal organophosphorate temephos (supplied by Cetrav), under the same conditions used in combat programs in the state of Ceará, Brazil. Larvae were exposed to the samples at room temperature during $24 \mathrm{~h}$ and mortality/survival registered after the first $5 \mathrm{~h}$ and $24 \mathrm{~h}$. Each test was run in triplicate and distilled water containing $0.04 \%$ Tween- 80 was used as control.

The persistence of larvicidal activity of the essential oil hydrolate was tested by running bioassays with the same samples (pure and 1:5 diluted hydrolate) after 15, 30 and 60 days.

Acute toxicity to mice was verified by i.p. injection ( 30 ml. $\mathrm{kg}^{-1}$ body weight) of diluted and pure hydrolate of $L$. sidoides according to Litchfield and Wilcoxon (1949).

L. sidoides essential oil and pure hydrolate caused $100 \%$ larval mortality almost instantaneously (1 to $5 \mathrm{~min}$ ). The diluted hydrolate at 1:2 and 1:5 proportions also caused $100 \%$ mortality, although after a much longer time, less than 20 and less than $30 \mathrm{~min}$, respectively. The dilution 1:10 showed $100 \%$ larval mortality after $24 \mathrm{~h}$, whilst the 1:20 diluted solution killed only $50 \%$ of tested larvae after the same time length. Thus, the hydrolate solution up to the dilution of 1:10 was still capable of causing $100 \%$ mortality, after $24 \mathrm{~h}$. It was seen that dilution (1:10) of the active principle(s) present in hydrolate was not sufficient to alter mortality rate, but increased the time needed for death to occur (Table I).

GL-chromatogram (data not shown) of L. sidoides hydrolate revealed that the alkyl phenol derivatives, carvacrol and thymol, were the main contituents (Figure). The larvicidal bioassays showed that thymol is the active principle of the essential oil hydrolate, since the results of
TABLE I

Larvicidal activity of Lippia sidoides essential oil against Aedes aegypti

\begin{tabular}{lcc}
\hline Dilution & Mortality (\%) & Time for death $^{b}$ \\
\hline Pure oil & $100 \pm 0$ & $<5 \mathrm{~min}$ \\
Pure hydrolate & $100 \pm 0$ & $<5 \mathrm{~min}$ \\
$1: 2$ & $100 \pm 0$ & $<5 \mathrm{~min}$ \\
$1: 5$ & $100 \pm 0$ & $<20 \mathrm{~min}$ \\
$1: 10$ & $100 \pm 0$ & $24 \mathrm{~h}$ \\
$1: 20$ & $50 \pm 8$ & $24 \mathrm{~h}$ \\
Distilled water + Tween-80 & $0 \pm 0$ & - \\
\hline
\end{tabular}

$a$ : values are means of three replicates \pm standard deviation $(\mathrm{n}=$ 10); $b$ : larval survival was monitored during the first $5 \mathrm{~h}$ and the final reading taken after $24 \mathrm{~h}$.

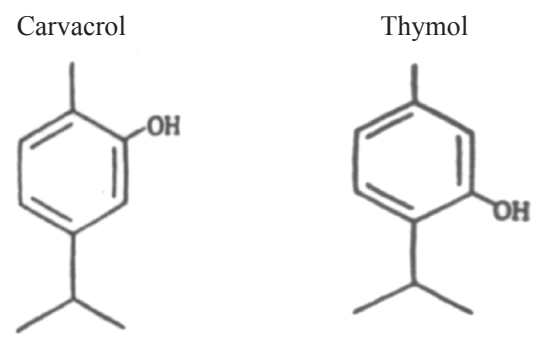

Chemical structure of carvacrol and thymol

bioassays with these isolated components revealed that only thymol has larvicidal activity (Table II). Thymol from concentration of $0.017 \%(\mathrm{w} / \mathrm{v})$ was capable of causing $100 \%$ larval mortality within $1 \frac{1}{2} \mathrm{~h}$, whilst at higher concentrations $100 \%$ mortality was achieved in $1 / 2 \mathrm{~h}$, showing that the dilution of active component delayed death time (Table II). Carvacrol was not capable of causing larval death not even when tested at the limit of its solubility coefficient $(0.04 \%)$. Thymol and carvacrol were also tested in combination at the same solution, $1: 1$, to examine whether the combination of each other could reduce the time needed to cause larval death. The results showed that

TABLE II

Larvicidal activity of thymol and carvacrol (main constituents of essential oil hydrolate from Lippia sidoides) against Aedes aegypti

\begin{tabular}{lcrc}
\hline Compound & $\begin{array}{c}\text { Concentration } \\
(\%)\end{array}$ & $\begin{array}{c}\text { Mortality } \\
(\%)^{a}\end{array}$ & Death time ${ }^{b}$ \\
\hline Thymol & 0.085 & $100 \pm 0$ & $30 \mathrm{~min}$ \\
& 0.040 & $100 \pm 0$ & $30 \mathrm{~min}$ \\
& 0.017 & $100 \pm 0$ & $11 / 2 \mathrm{~h}$ \\
Carvacrol & 0.008 & $0 \pm 0$ & $24 \mathrm{~h}$ \\
Thymol + carvacrol & $0.040+0.040$ & $100 \pm 0$ & $30 \mathrm{~min}$ \\
Distilled water + & - & $0 \pm 0$ & - \\
Tween-80 & & &
\end{tabular}

$\bar{a}$ : values are means of three replicates and standard deviation; $b$ : larval survival was monitored during the first $5 \mathrm{~h}$ and the final reading taken after $24 \mathrm{~h}$. 
carvacrol had no action in the toxic activity. Therefore, the data suggest that thymol is the active toxic principle of $L$. sidoides hydrolate with larvicidal activity against $A$. aegypti.

When these results were compared with those of the organophosphorate compound temephos (data not shown), it turned out that the hydrolate of L. sidoides essential oil was more potent, causing $100 \%$ larval mortality in a shorter time (less than $5 \mathrm{~min}$ ) than that caused by temephos (after $24 \mathrm{~h}$ ) at the concentration (1 ppm) used in programs of mosquito combat in Brazil. L. sidoides hydrolate has the tangible advantage of being a potentially low cost of production and lower toxicity (The Merck Index 1976, EPA 2002).

As to the persistence of effective larvicidal action, pure and 1:5 diluted hydrolate both continued to cause $100 \%$ mortality even after 60 days, but the time necessary to cause $100 \%$ mortality was increased from less than 5 $\mathrm{min}$ to $10 \mathrm{~min}$ with the pure hydrolate and from $20 \mathrm{~min}$ to $60 \mathrm{~min}$ with the diluted hydrolate. These results confirm the known fact that $L$. sidoides essential oil components, and particularly thymol, are quite stable (The Good Scents Company 2002).

The results of acute toxicity tests with mice showed that i.p. injections of pure hydrolate did not cause any adverse effects or mortality. It is well known that thymol shows low toxicity, with a $\mathrm{DL}_{50}$ of $1.8 \mathrm{~g} . \mathrm{kg}^{-1}$ body weight when administered per os to rats whilst carvacrol shows higher toxicity when compared to thymol, with $\mathrm{DL}_{50}$ of $100 \mathrm{mg}$. kg ${ }^{-1}$ body weight when administered per os to rabbits (The Merck Index 1976).

In conclusion, the results are rather promising considering the following arguments: L. sidoides is an easily cultivated plant in warm regions; the hydrolate of its essential oil may be prepared with simple technology and high yield; the larvicidal activity of the oil is very potent and persistent; and no apparent deleterious acute or chronic (work in progress) effects upon the animals have been observed.

\section{REFERENCES}

Bantim MB 2000. Efeito Larvicida do Hidrolato de Lippia sidoides Cham., Monograph, Universidade Federal do Ceará, Fortaleza, 42 pp.

Cepleanu F 1993. Validation and Application of Three Benchtop Bioassays for Screening of Crude Plant Extracts and Subsequent Activity-guided Isolation, $\mathrm{PhD}$ Thesis, Faculté des Sciences, Université de Lausanne, Lausanne, 186 pp.

Consoli RA, Oliveira RL 1994. Principais Mosquitos de Importância Sanitária no Brasil, Fiocruz, Rio de Janeiro, 225 pp.

EPA-Environmental Protection Agency. Thymol: reregistration eligibility decisions (RED) fact sheet. Available at: www.epa.gov/docs/REDs/factsheets/3143fact.pdf. Accessed on August 26, 2002.

Gluber D 1989. Aedes aegypti and Aedes aegypti-borne disease control in the 1990's: top down or bottom up. Am J Trop Med Hyg 40: 571-578.

Litchfield Jr JT, Wilcoxon FA 1949. A simplified method for evaluation of dose-effect experiments. J Pharmacol Exp Ther 96: 99-104.

Maillard M, Marston A, Hostettmann K 1993. Search for molluscicidal and larvicidal agents from plants. In M Balandrin, Human Medicinal Agents From Plants, American Chemical Society, Washington DC.

Matos FJA 1994. Farmácias Vivas, UFC, Fortaleza, 219 pp.

Thangam TS, Kathiresan K 1991. Mosquito larvicidal effect of seaweed extracts. Bot Mar 34: 433-435.

The Good Scents Company. Material Safety data sheet. Thymol: stability and reactivity. Available at www.my.execp.com/ goodscnt/msds/md101476.html. Accessed on August 26, 2002.

The Merck Index 1976. An Encyclopedia of Chemicals and Drugs, 9th ed., Merck Co., Rahway, NJ, p. 238-9, 1214. 